\title{
Overactive bladder: pharmacological treatment
}

\author{
BeXIga hIPERATIVA: tRATAMENTO FARMACOLÓgico
}

\author{
Authorship: Brazilian Society of Urology (SBU) \\ Participants: José Carlos Truzzi ${ }^{1}$, Antonio Silvinato ${ }^{1}$, Wanderley Marques Bernardo ${ }^{2}$ \\ Final draft: August 21, 2016
}

'Sociedade Brasileira de Urologia. Universidade Federal de São Paulo. Hospital Alemão Oswaldo Cruz, São Paulo, SP, Brazil

${ }^{2}$ Associação Médica Brasileira (AMB)

The Guidelines Project, an initiative of the Brazilian Medical Association, aims to combine information from the medical field in order to standardize procedures to assist the reasoning and decision-making of doctors.

The information provided through this project must be assessed and criticized by the physician responsible for the conduct that will be adopted, depending on the conditions and the clinical status of each patient.

\section{DESCRIPTION OF EVIDENCE COLLECTION METHOD}

The review of scientific articles in this guideline was carried out from MEDLINE, Cochrane and SciELO databases. The search for evidence was based on actual clinical scenarios and used keywords (MeSH terms) grouped in the following syntax: (Overactive Detrusor OR Overactive Urinary Bladder OR Urinary Bladder, Overactive OR Urinary Incontinence) AND (Cholinergic Antagonists OR Anticholinergic Agents OR Agents, Cholinergic Blocking OR Muscarinic Antagonists OR Antimuscarinics OR Parasympatholytics OR Antispasmodics OR Imipramine OR Beta-3 Adrenergic Receptor Agonist OR Mirabegron OR Adrenergic Beta-3 Receptor Agonists OR Beta-3 Adrenergic Agonist). The articles were selected after a critical evaluation of the strength of scientific evidence, and the publications of greatest strength were used for recommendation. The recommendations were elaborated from discussions in the group. The entire guideline was reviewed by an independent group specializing in evidence-based clinical recommendation.

\section{Grades of Recommendation and LeVels OF EVIDENCE}

- A: Experimental or observational studies of higher consistency.

- B: Experimental or observational studies of lower consistency.

- C: Cases reports (non-controlled studies).

- D: Opinion without critical evaluation, based on consensus, physiological studies or animal models.

\section{Objective}

To describe the main recommendations in the pharmacological treatment of overactive bladder.

\section{INTRODUCTION}

Overactive bladder syndrome is defined by the International Continence Society (ICS) as a clinical syndrome characterized by lower urinary tract dysfunction that includes urgency symptoms, with or without urge incontinence, usually accompanied by pollakiuria and nocturia, in the absence of metabolic and infectious factors or associated diseases. ${ }^{1}$ (D) In order to minimize symptoms and improve quality of life, the main therapeutic modalities are non-pharmacological (general measures, behavioral and physiotherapeutic treatment) and pharmacological. Antimuscarinics represent the first line of medical treatment for patients with overactive bladder, both idiopathic and secondary to the underlying neurological disease., ${ }^{2,3}$ (D) They are used to stabilize the detrusor muscle, through binding and blocking muscarinic receptors. This results in improvement of bladder functional capacity, reduction of detrusor overactivity and improvement of symptoms. ${ }^{4}$ (A) Patients with neurogenic detrusor overactivity may need higher doses than patients with idiopathic detrusor overactivity. ${ }^{5}(\mathbf{A})^{6}(\mathbf{B})$

\section{What is the Role played by ANTIMUSCARINIC DRUGS IN THE TREATMENT OF THE OVERACTIVE BLADDER?}

Bladder contractions are due to the cholinergic stimulus of muscarinic receptors. Five types of receptors are well-known (M1 to M5). In the bladder, types M2 and M3 occur, the latter being the most important for contracting the detrusor muscle. Anticholinergic or muscarinic antagonists act through parasympatholytic action, which prevents the interaction of acetylcholine with the receptor by binding to the muscarinic receptors in the postganglionic synaptic cleft, reducing the amplitude of the contrac- 
tions, increasing the volume at the first contraction, and thus the functional capacity of the bladder. These are the drugs most used in the treatment of overactive bladder syndrome, with recognized superiority over placebo. ${ }^{7,8}$ (A) However, none of the currently available drugs selectively targets muscarinic receptors M2 or M3 in the bladder, where they predominate. They therefore cause unpleasant systemic effects, particularly related to salivary secretion and intestinal function, which are often intense enough to lead the patient to cease treatment. Potential side effects of antimuscarinic drugs include dry mouth, visual turbidity and inhibition of intestinal peristalsis, causing constipation. Other central effects are dizziness, memory loss and drowsiness.

\section{Oxybutynin chloride}

This is a tertiary amine with mixed action, commonly used orally, which associates antispasmodic, antimuscarinic and local anesthetic action on the smooth muscle, and is currently the most widely used drug. ${ }^{9}$ (A) Its main effect, although not specific, is the inhibition of M1 and M3 receptors. It was the first anticholinergic used in the treatment of overactive bladder, with success rates ranging from 61 to $86 \%$, but with limited effectiveness due to side effects. ${ }^{10-12}$ (D) It is available as immediate release, the first agent of this class to be used in the treatment of overactive bladder symptoms, or extended release formulation. Other possibilities of administration aiming to minimize the side effects, but not commercialized in Brazil, include a transdermal patch, intravesical and topical gel. In these forms, it is possible to control the serum fluctuations of the drug, which are responsible for the appearance of most of the side effects.

\section{Tolterodine tartrate}

It is a tertiary amine with potent antimuscarinic action that demonstrated eight times greater affinity for the muscarinic receptors in the bladder (M2) than in the salivary glands. ${ }^{10}$ (D) It is also available in forms of immediate and extended release, the latter having shown greater tolerability and adherence by patients due to less serum fluctuation. ${ }^{9}$ (A) Its greater selectivity gives it a better tolerability profile. ${ }^{13}$ (D) A randomized clinical trial analyzing the two forms of presentation identified better results with the extended release form, in addition to more discrete side effects. ${ }^{14}$ (A)

\section{Oxybutynin chloride versus tolterodine tartrate}

Numerous studies have compared the two drugs in different dosages, formulations, release forms and treatment times. Direct comparisons between oxybutynin and tolterodine suggest that both drugs have similar effects on urinary incontinence episodes, although studies report better results on the number of episodes involving urge incontinence, urinary incontinence and urinary frequency using extended release oxybutynin compared with immediate release tolterodine. ${ }^{15-21}$ (A) However, when comparing the two agents in long-acting presentation, tolterodine was shown to be better tolerated by patients. ${ }^{14}$ (A) Regarding quality of life and data on the perception of cure or improvement of symptoms identified by the patients, both treatments were similar. ${ }^{22,23}$ (A) As for tolerability, subjects receiving tolterodine, either immediate or extended release, were less likely to cease treatment because of adverse events (34-60\%). ${ }^{17,21,23}$ (A)

\section{Darifenacin hydrobromide}

This anticholinergic agent is highly selective for M3 receptors, reducing the side effects of $\mathrm{M} 1$ and $\mathrm{M} 2$ receptor blockade. Placebo-controlled studies have demonstrated its efficacy in treating patients with overactive bladder-related symptoms, proving to be effective in reducing the number of urge incontinence episodes as well as in voiding frequency and intensity of urgency. ${ }^{24-27}$ (A) However, despite its selectivity, side effects are observed, affecting about half of the patients. ${ }^{24}$ (A) Central effects are reduced by selectivity and low penetration in the central nervous system. ${ }^{28}$ (B)

\section{Solifenacin succinate}

This is a long-acting M3 receptor-specific muscarinic receptor antagonist, which allows for a single daily dose. Its use to treat overactive bladder has resulted in improvements in urgency and urge incontinence symptoms, also increasing volume per urination. ${ }^{29,30}(\mathbf{A})^{31}$ (B) Adverse effects do not differ from those of the other drugs cited above and have been reported as mild and moderate. Randomized studies have shown a lower risk of cognitive impairment in elderly patients receiving solifenacin compared to oxybutynin. ${ }^{32,33}$ (A)

\section{Solifenacin succinate versus tolterodine tartrate}

Comparisons between solifenacin and tolterodine suggest better results with the former regarding quality of life, urgency and urge incontinence symptoms, and perceived improvement of symptoms identified by patients, although studies have shown similar effects between both drugs. ${ }^{30,34-36}$ (A) ${ }^{37,38}$ (B) Some studies have reported dry mouth complaints less commonly in subjects receiving solifenacin, others have shown similar or even superior results with 
the use of this drug. However, therapeutic withdrawals related to adverse events were similar. ${ }^{35}(\mathbf{A})^{38}$ (B)

\section{Trospium chloride}

It is a quaternary amine and, as such, it does not cross the blood-brain barrier, significantly reducing side effects on the central nervous system. Through an anticholinergic effect, it has efficacy in the treatment of patients with symptoms related to overactive bladder. ${ }^{39}$ (A) It is a potent competitor of acetylcholine, with high affinity for M1, M2 and M3 receptors. Randomized placebo-controlled studies comparing trospium chloride to oxybutynin showed similar efficacy and side effects. ${ }^{40-42}$ (A)

\section{Recommendation}

The main therapeutic modality of overactive bladder syndrome is clinical pharmacological treatment, and anticholinergic agents are currently the most widely used drugs in the management of this condition. These substances are associated with side effects, which lead the patient to abandon treatment in most cases. They are contraindicated in individuals with closed angle glaucoma and should be used with caution in cases of infravesical obstruction due to the risk of urinary retention. (A)

\section{What is the Role played by ANTIDEPRESSANTS IN THE TREATMENT OF THE OVERACTIVE BLADDER?}

These drugs have intense systemic anticholinergic action, in addition to the inhibition of serotonin reuptake. In this class, the drug most commonly used to treat overactive bladder has been imipramine, which is a tricyclic antidepressant. Peripherally, it has an important anticholinergic effect, but the antimuscarinic effect on the detrusor muscles is limited. It also has an indirect alpha-adrenergic action, as it inhibits the reuptake of noradrenalin and serotonin, promoting relaxation of the detrusor muscle and increased intraurethral pressure. ${ }^{30}(\mathrm{D})$ It reduces the episodes of urinary loss, being an alternative especially in cases of mixed urinary incontinence. Although studies have shown a beneficial effect of this drug, with reduction or improvement of incontinence, they comprise small series of cases or uncontrolled trials evaluating the combined effect of other drugs associated with imipramine. ${ }^{43}$ (D) A small placebo-controlled clinical trial did not show a significant difference between treatments. ${ }^{44}$ (B) Adverse effects, mainly cardiovascular events leading to the onset of arrhythmias, have limited their use. ${ }^{45-48}$ (A) Side effects include dry mouth, constipation, tachycardia and blurred vision, in addition to fatigue, excessive sweating, headache, muscle tremors and epigastric discomfort.

\section{Recommendation}

Imipramine is the tricyclic antidepressant most commonly used in the treatment of overactive bladder syndrome, despite the lack of randomized clinical trials. It should not be prescribed for patients with mania-type psychiatric disorders and those who are taking MAO inhibitors. Its clinical application may be limited in patients at increased risk of cardiac arrhythmias (prolonged QT interval). (D)

\section{What IS THE ROLE PLAYEd BY ALPHA- -BLOCKERS IN THE TREATMENT OF THE OVERACTIVE BLADDER?}

$\alpha$-blockers have the effect of improving symptoms related to overactive bladder. However, there is currently no scientific information to support its clinical use. ${ }^{49}$ (B)

\section{Recommendation}

Despite studies showing improvement of symptoms, the use of $\alpha$-blockers to treat overactive bladder is not yet routinely indicated. (B)

\section{What is the ROLE PLAYEd by beta-Agonists IN THE TREATMENT OF THE OVERACTIVE BLADDER?}

$\beta 3$-adrenergic receptor agonists represent a new class of drugs for the treatment of idiopathic overactive bladder. Three subtypes of adrenergic receptors $(\beta 1, \beta 2$ and $\beta 3)$ were identified in detrusor muscle and human urothelium, with a predominant expression of $\beta 3$ receptors in the detrusor muscle. Activation of $\beta 3$ adrenergic receptors causes relaxation of the detrusor muscle secondary to the activation of adenylyl cyclase and formation of adenosine cyclic monophosphate. Mirabegron is the first $\beta 3$ agonist to be used in clinical practice. ${ }^{50-53}$ (D) To assess the efficacy and tolerability of this drug therapy in the treatment of idiopathic overactive bladder (IOAB), two phase $\mathrm{II}^{54,55}(\mathrm{~B})$ and six phase $\mathrm{III}^{56-61}$ (A) randomized clinical trials (RCTs) recruited more than 10,500 adult patients. Of these, seven were randomized, double-blind and placebo-controlled with follow-up of four (one study) and 12 (six studies) weeks, and one was non-placebo-controlled (vs. tolterodine) with 12-month follow-up. All studies recruited male and female patients over 18 years of age with IOAB symptoms for at least three months prior to the start of the study. Most studies compared several doses of mirabegron to placebo and/or long-acting (LA) tolterodine, $4 \mathrm{mg}$, and 
the primary efficacy endpoints considered were number of micturitions and number of episodes of incontinence over 24 hours (results expressed as average).

A systematic review (SR), with all the studies above, concludes that mirabegron is as effective as most antimuscarinics, including LA tolterodine, $4 \mathrm{mg}$, compared to placebo in relation to the primary outcomes (number of micturitions and number of episodes of incontinence over 24 hours). Regarding tolerability, the data suggest that patients who took mirabegron had a similar rate of adverse events compared to those in the placebo group, whereas the rate in the antimuscarinic group was the highest. ${ }^{62}$ (A)

The most common adverse events observed with mirabegron include: hypertension, nasopharyngitis, urinary tract infections, headache, constipation, upper respiratory tract infection, arthralgia, diarrhea, tachycardia, abdominal pain and fatigue. ${ }^{63}(\mathbf{A})$

A SR with meta-analysis included data from six $\operatorname{RCTs}^{54,55,57-59}$ and showed that mirabegron (25, 50 and $100 \mathrm{mg}$ ) was more effective than placebo in treatment of $\mathrm{IOAB}$ regardless of dose, in the analysis of the following outcomes: number of episodes of incontinence and number of micturitions in 24 hours. Compared with placebo, mirabegron showed a similar risk of adverse events. Compared with tolterodine, mirabegron was more effective in terms of mean number of incontinence episodes over 24 hours (MD -0.25; 95CI -0.43--0.06; $\mathrm{p}=0.009$ ), but there was no difference in mean number of micturitions over 24 hours (MD -0.17; 95CI -0.35-0.01; $\mathrm{p}=0.07$ ). Mirabegron also showed a lower rate of adverse reaction in this comparison [OR 0.9; 95CI 0.8-1.0; $\mathrm{P}=0.04] .{ }^{64}(\mathbf{A})$

\section{Recommendation}

$\beta 3$ adrenergic receptor agonists have the effect of improving symptoms related to overactive bladder. Patients who may benefit from mirabegron include those who are unsuitable for the use of antimuscarinics or who have already presented adverse events with them. (A)

\section{Combination therapy (mirabegron AND ANTIMUSCARINICS)}

A multicenter, double-blind, placebo-controlled, phase II RCT with a follow-up of 12 weeks included 1,306 female and male patients $\geq 18$ years with symptoms of $\mathrm{IOAB} \geq 3$ months and assessed the efficacy of combination solifenacin/mirabegron compared to solifenacin $5 \mathrm{mg}$ alone. The secondary endpoint was to explore the dose-response relationship (solifenacin $2.5,5$ or $10 \mathrm{mg}$ and mirabegron 25 or $50 \mathrm{mg}$ ) and safety/tolerability compared to placebo and monotherapy. Combination therapy with mirabegron/ solifenacin demonstrated a significant improvement over monotherapy (solifenacin $5 \mathrm{mg}$ ) as to volume eliminated by urination, voiding frequency and urgency, without increasing adverse events associated with antimuscarinic therapy, except for constipation. ${ }^{65}$ (B)

\section{Recommendation}

Combination therapy solifenacin/mirabegron may be an option for solifenacin $5 \mathrm{mg}$ as monotherapy in patients with IOAB. (B)

\section{RefEREnCES}

1. Abrams P, Cardozo L, Fall M, Griffiths D, Rosier P, Ulmsten U, et al.; Standardisation Sub-committee of the International Continence Society The standardisation of terminology of lower urinary tract function: report from the Standardisation Sub-committee of the International Continence Society. Neurourol Urodyn. 2002; 21(2):167-78.

2. Kennelly MJ, Devoe WB. Overactive bladder: pharmacologic treatments in the neurogenic population. Rev Urol. 2008; 10(3):182-91.

3. Stöhrer M, Blok B, Castro-Diaz D, Chartier-Kastler E, Del Popolo G, Kramer $\mathrm{G}$, et al. EAU guidelines on neurogenic lower urinary tract dysfunction. Eur Urol. 2009; 56(1):81-8.

4. Amend B, Hennenlotter J, Schäfer T, Horstmann M, Stenzl A, Sievert KD. Effective treatment of neurogenic detrusor dysfunction by combined high-dosed antimuscarinics without increased side-effects. Eur Urol. 2008; 53(5):1021-8.

5. Menarini M, Del Popolo G, Di Benedetto P, Haselmann J, Bödeker RH, Schwantes U, et al.; TcP128-Study Group. Trospium chloride in patients with neurogenic detrusor overactivity: is dose titration of benefit to the patients? Int J Clin Pharmacol Ther. 2006; 44(12):623-32.

6. Horstmann M, Schaefer T, Aguilar Y, Stenzl A, Sievert KD. Neurogenic bladder treatment by doubling the recommended antimuscarinic dosage. Neurourol Urodyn. 2006; 25(5):441-5.

7. Chapple CR, Khullar V, Gabriel Z, Muston D, Bitoun CE, Weinstein D. The effects of antimuscarinic treatments in overactive bladder: an update of a systematic review and meta-analysis. Eur Urol. 2008; 54(3):543-62.

8. Herbison P, Hay-Smith J, Ellis G, Moore K. Effectiveness of anticholinergic drugs compared with placebo in the treatment of overactive bladder: systematic review. BMJ. 2003; 326(7394):841-4.

9. Madhuvrata P, Cody JD, Ellis G, Herbison GP, Hay-Smith EJ. Which anticholinergic drug for overactive bladder symptoms in adults. Cochrane Database Syst Rev. 2012; 1:CD005429.

10. Muhlstein J, Deval B. [Anticholinergic drugs in overactive bladder]. Gynecol Obstet Fertil. 2008; 36(1):90-6.

11. Staskin DR, MacDiarmid SA. Using anticholinergics to treat overactive bladder: the issue of treatment tolerability. Am J Med 2006; 119(3 Suppl 1):9-15.

12. Yoshimura N, Chancellor MB. Current and future pharmacological treatment for overactive bladder. J Urol. 2002; 168(5):1897-913.

13. Appell RA. Pharmacotherapy for overactive bladder: an evidence-based approach to selecting an antimuscarinic agent. Drugs. 2006; 66(10):1361-70

14. Van Kerrebroeck P, Kreder K, Jonas U, Zinner N, Wein A; Tolterodine Study Group. Tolterodine once-daily: superior efficacy and tolerability in the treatment of the overactive bladder. Urology. 2001; 57(3):414-21.

15. Diokno AC, Appell RA, Sand PK, Dmochowski RR, Gburek BM, Klimberg IW, et al.; OPERA Study Group. Prospective, randomized, double-blind study of the efficacy and tolerability of the extended-release formulations of oxybutynin and tolterodine for overactive bladder: results of the OPERA trial. Mayo Clin Proc. 2003; 78(6):687-95

16. Dmochowski RR, Sand PK, Zinner NR, Gittelman MC, Davila GW, Sanders SW; Transdermal Oxybutynin Study Group. Comparative efficacy and safety of transdermal oxybutynin and oral tolterodine versus placebo in previously treated patients with urge and mixed urinary incontinence. Urology. 2003; 62(2):237-42.

17. Abrams P, Freeman R, Anderström C, Mattiasson A. Tolterodine, a new antimuscarinic agent: as effective but better tolerated than oxybutynin in patients with an overactive bladder. Br J Urol. 1998; 81(6):801-10. 
18. Appell RA, Sand P, Dmochowski R, Anderson R, Zinner N, Lama D, et al.; Overactive Bladder: Judging Effective Control and Treatment Study Group. Prospective randomized controlled trial of extended-release oxybutynin chloride and tolterodine tartrate in the treatment of overactive bladder: results of the OBJECT Study. Mayo Clin Proc. 2001; 76(4):358-63.

19. Sand PK, Miklos J, Ritter H, Appell R. A comparison of extended-release oxybutynin and tolterodine for treatment of overactive bladder in women. Int Urogynecol J Pelvic Floor Dysfunct. 2004; 15(4):243-8.

20. Anderson RU, MacDiarmid S, Kell S, Barada JH, Serels S, Goldberg RP. Effectiveness and tolerability of extended-release oxybutynin vs extended-release tolterodine in women with or without prior anticholinergic treatment for overactive bladder. Int Urogynecol J Pelvic Floor Dysfunct. 2006; 17(5):502-11

21. Homma Y, Paick JS, Lee JG, Kawabe K; Japanese and Korean Tolterodine Study Group. Clinical efficacy and tolerability of extended-release tolterodine and immediate-release oxybutynin in Japanese and Korean patients with an overactive bladder: a randomized, placebo-controlled trial. BJU Int. 2003; 92(7):741-7.

22. Homma Y, Kawabe K. Health-related quality of life of Japanese patients with overactive bladder treated with extended-release tolterodine or immediate-release oxybutynin: a randomized, placebo-controlled trial. World J Urol. 2004; 22(4):251-6.

23. Lee JG, Hong JY, Choo MS, Kwon HY, Chung DY, Lee KS, et al. Tolterodine: as effective but better tolerated than oxybutynin in Asian patients with symptoms of overactive bladder. Int J Urol. 2002; 9(5):247-52.

24. Haab F, Stewart L, Dwyer P. Darifenacin, an M3 selective receptor antagonist, is an effective and well-tolerated once-daily treatment for overactive bladder. Eur Urol. 2004; 45(4):420-9; discussion 429.

25. Chapple C, Steers W, Norton P, Millard R, Kralidis G, Glavind K, et al. A pooled analysis of three phase III studies to investigate the efficacy, tolerability and safety of darifenacin, a muscarinic M3 selective receptor antagonist, in the treatment of overactive bladder. BJU Int. 2005; 95(7):993-1001.

26. Zinner N, Susset J, Gittelman M, Arguinzoniz M, Rekeda L, Haab F. Efficacy, tolerability and safety of darifenacin, an $\mathrm{M}(3)$ selective receptor antagonist: an investigation of warning time in patients with OAB. Int J Clin Pract. 2006; 60(1):119-26.

27. Cardozo L, Dixon A. Increased warning time with darifenacin: a new concept in the management of urinary urgency. J Urol. 2005; 173(4):1214-8.

28. Kay G, Crook T, Rekeda L, Lima R, Ebinger U, Arguinzoniz M, et al Differential effects of the antimuscarinic agents darifenacin and oxybutynin ER on memory in older subjects. Eur Urol. 2006; 50(2):317-26.

29. Cardozo L, Lisec M, Millard R, van Vierssen Trip O, Kuzmin I, Drogendijk TE, et al. Randomized, double-blind placebo controlled trial of the once daily antimuscarinic agent solifenacin succinate in patients with overactive bladder. J Urol. 2004; 172(5 Pt 1):1919-24.

30. Andersson KE, Sjögren C. Aspects on the physiology and pharmacology of the bladder and urethra. Prog Neurobiol. 1982; 19(1-2):71-89.

31. Abrams P, Swift S. Solifenacin is effective for the treatment of OAB dry patients: a pooled analysis. Eur Urol. 2005; 48(3):483-7.

32. Wagg A, Dale M, Tretter R, Stow B, Compion G. Randomised, multicentre, placebo-controlled, double-blind crossover study investigating the effect of solifenacin and oxybutynin in elderly people with mild cognitive impairment: the SENIOR study. Eur Urol. 2013; 64(1):74-81.

33. Wesnes KA, Edgar C, Tretter RN, Bolodeoku J. Exploratory pilot study assessing the risk of cognitive impairment or sedation in the elderly following single doses of solifenacin $10 \mathrm{mg}$. Expert Opin Drug Saf. 2009; 8(6):615-26.

34. Chapple CR, Rechberger T, Al-Shukri S, Meffan P, Everaert K, Huang M, et al. Randomized, double-blind placebo- and tolterodine-controlled trial of the once-daily antimuscarinic agent solifenacin in patients with symptomatic overactive bladder. BJU Int. 2004; 93(3):303-10.

35. Chapple CR, Martinez-Garcia R, Selvaggi L, Toozs-Hobson P, Warnack W, Drogendijk T, et al. A comparison of the efficacy and tolerability of solifenacin succinate and extended release tolterodine at treating overactive bladder syndrome: results of the STAR trial. Eur Urol. 2005; 48(3):464-70.

36. Chapple CR, Fianu-Jonsson A, Indig M, Khullar V, Rosa J, Scarpa RM, et al. Treatment outcomes in the STAR study: a subanalysis of solifenacin $5 \mathrm{mg}$ and tolterodine ER 4 mg. Eur Urol. 2007; 52(4):1195-203.

37. Chapple CR, Araño P, Bosch JL, De Ridder D, Kramer AE, Ridder AM Solifenacin appears effective and well tolerated in patients with symptomatic idiopathic detrusor overactivity in a placebo- and tolterodine-controlled phase 2 dose-finding study. BJU Int. 2004; 93(1):71-7.
38. Ho CH, Chang TC, Lin HH, Liu SP, Huang KH, Yu HJ. Solifenacin and tolterodine are equally effective in the treatment of overactive bladder symptoms. J Formos Med Assoc. 2010; 109(10):702-8.

39. Zinner N, Gittelman M, Harris R, Susset J, Kanelos A, Auerbach S; Trospium Study Group. Trospium chloride improves overactive bladder symptoms: a multicenter phase III trial. J Urol. 2004; 171(6 Pt 1):2311-5, quiz 2435.

40. Halaska M, Ralph G, Wiedemann A, Primus G, Ballering-Bruhl B, Höfner $\mathrm{K}$, et al. Controlled, double-blind, multicentre clinical trial to investigate long-term tolerability and efficacy of trospium chloride in patients with detrusor instability. World J Urol. 2003; 20(6):392-9.

41. Madersbacher H, Stöhrer M, Richter R, Burgdörfer H, Hachen HJ, Mürtz G. Trospium chloride versus oxybutynin: a randomized, double-blind multicentre trial in the treatment of detrusor hyper-reflexia. Br J Urol. 1995; 75(4):452-6

42. Zellner M, Madersbacher H, Palmtag H, Stöhrer M, Bödeker RH; P195 Study Group. Trospium chloride and oxybutynin hydrochloride in a german study of adults with urinary urge incontinence: results of a 12-week, multicenter, randomized, double-blind, parallel- group, flexible-dose noninferiority trial. Clin Ther. 2009; 31(11):2519-39.

43. Hunsballe JM, Djurhuus JC. Clinical options for imipramine in the management of urinary incontinence. Urol Res. 2001; 29(2):118-25.

44. Castleden CM, Duffin HM, Gulati RS. Double-blind study of imipramine and placebo for incontinence due to bladder instability. Age Ageing. 1986; 15(5):299-303.

45. Martin MR, Schiff AA. Fluphenazine/nortriptyline in the irritable bladder syndrome. A double-blind placebo controlled study. Br J Urol. 1984; 56(2):178-9.

46. Sert A, Aypar E, Odabas D, Aygul MU. Temporary cardiac pacemaker in the treatment of junctional rhythm and hypotension due to imipramine intoxication. Pediatr Cardiol. 2011; 32(4):521-4.

47. Nykamp DL, Blackmon CL, Schmidt PE, Roberson AG. QTc prolongation associated with combination therapy of levofloxacin, imipramine, and fluoxetine. Ann Pharmacother. 2005; 39(3):543-6.

48. Witchel HJ, Hancox JC, Nutt DJ. Psychotropic drugs, cardiac arrhythmia, and sudden death. J Clin Psychopharmacol. 2003; 23(1):58-77.

49. Chang SJ, Chiang IN, Yu HJ. The effectiveness of tamsulosin in treating women with voiding difficulty. Int J Urol. 2008; 15(11):981-5.

50. Chapple CR. $\beta 3$-agonist therapy: a new advance in the management of overactive bladder? Eur Urol. 2012; 62(5):841-2.

51. Andersson KE, Arner A. Urinary bladder contraction and relaxation: physiology and pathophysiology. Physiol Rev. 2004; 84(3):935-86.

52. Otsuka A, Shinbo H, Matsumoto R, Kurita Y, Ozono S. Expression and functional role of beta-adrenoceptors in the human urinary bladder urothelium. Naunyn Schmiedebergs Arch Pharmacol. 2008; 377(46):473-81.

53. Igawa Y, Yamazaki Y, Takeda H, Kaidoh K, Akahane M, Ajisawa Y, et al Relaxant effects of isoproterenol and selective beta3-adrenoceptor agonists on normal, low compliant and hyperreflexic human bladders. J Urol. 2001; 165(1):240-4

54. Chapple CR, Amarenco G, López Aramburu MA, Everaert K, Liehne J, Lucas $\mathrm{M}$, et al.; BLOSSOM Investigator Group. A proof-of-concept study: mirabegron, a new therapy for overactive bladder. Neurourol Urodyn. 2013; 32(8):1116-22.

55. Chapple CR, Dvorak V, Radziszewski P, Van Kerrebroeck P, Wyndaele JJ, Bosman B, et al.; Dragon Investigator Group. A phase II dose-ranging study of mirabegron in patients with overactive bladder. Int Urogynecol J. 2013; 24(9):1447-58.

56. Chapple CR, Kaplan SA, Mitcheson D, Klecka J, Cummings J, Drogendijk $\mathrm{T}$, et al. Randomized double-blind, active-controlled phase 3 study to assess 12 -month safety and efficacy of mirabegron, a $\beta(3)$-adrenoceptor agonist, in overactive bladder. Eur Urol. 2013; 63(2):296-305.

57. Herschorn S, Barkin J, Castro-Diaz D, Frankel JM, Espuna-Pons M, Gousse $\mathrm{AE}$, et al. A phase III, randomized, double-blind, parallel-group, placebocontrolled, multicentre study to assess the efficacy and safety of the $\beta_{3}$ adrenoceptor agonist, mirabegron, in patients with symptoms of overactive bladder. Urology. 2013; 82(2):313-20.

58. Khullar V, Amarenco G, Angulo JC, Cambronero J, Høye K, Milsom I, et al. Efficacy and tolerability of mirabegron, a $\beta(3)$-adrenoceptor agonist, in patients with overactive bladder: results from a randomised EuropeanAustralian phase 3 trial. Eur Urol. 2013; 63(2):283-95. 
59. Nitti VW, Auerbach S, Martin N, Calhoun A, Lee M, Herschorn S. Results of a randomized phase III trial of mirabegron in patients with overactive bladder. J Urol. 2013; 189(4):1388-95.

60. Kuo HC, Lee KS, Na Y, Sood R, Nakaji S, Kubota Y, et al. Results of a randomized, double-blind, parallel-group, placebo- and active-controlled, multicenter study of mirabegron, a $\beta 3$-adrenoceptor agonist, in patients with overactive bladder in Asia. Neurourol Urodyn. 2015 34(7):685-92.

61. Yamaguchi O, Marui E, Kakizaki H, Homma Y, Igawa Y, Takeda M, et al Phase III, randomised, double-blind, placebo-controlled study of the $\beta 3$ adrenoceptor agonist mirabegron, $50 \mathrm{mg}$ once daily, in Japanese patients with overactive bladder. BJU Int. 2014; 113(6):951-60.
62. Thiagamoorthy G, Kotes S, Zacchè M, Cardozo L. The efficacy and tolerability of mirabegron, a $\beta 3$ adrenoceptor agonist, in patients with symptoms of overactive bladder. Ther Adv Urol. 2016; 8(1):38-46

63. Bragg R, Hebel D, Vouri SM, Pitlick JM. Mirabegron: a beta-3 agonist for overactive bladder. Consult Pharm. 2014; 29(12):823-37.

64. Wu T, Duan X, Cao CX, Peng CD, Bu SY, Wang KJ. The role of mirabegron in overactive bladder: a systematic review and meta-analysis. Urol Int. 2014; 93(3):326-37.

65. Abrams P, Kelleher C, Staskin D, Rechberger T, Kay R, Martina R, et al. Combination treatment with mirabegron and solifenacin in patients with overactive bladder: efficacy and safety results from a randomised, double-blind, dose-ranging, phase 2 study (Symphony). Eur Urol. 2015; 67(3):577-88 